\title{
Establishment of a multimarker qPCR panel for the molecular characterization of circulating tumor cells in blood samples of metastatic breast cancer patients during the course of palliative treatment
}

\author{
Maren Bredemeier ${ }^{1}$, Philippos Edimiris ${ }^{1}$, Mitra Tewes ${ }^{2}$, Pawel Mach ${ }^{1}$, Bahriye Aktas ${ }^{1}$, \\ Doreen Schellbach ${ }^{3}$, Jenny Wagner ${ }^{3}$, Rainer Kimmig ${ }^{1}$, Sabine Kasimir-Bauer ${ }^{1}$ \\ ${ }^{1}$ Department of Gynecology and Obstetrics, University Hospital Essen, University of Duisburg-Essen, Essen, Germany \\ ${ }^{2}$ Department of Medical Oncology, West German Cancer Center, University Hospital Essen, University of Duisburg-Essen, \\ Essen, Germany \\ ${ }^{3}$ QIAGEN Hannover GmbH, Langenhagen, Germany \\ Correspondence to: Maren Bredemeier, email: maren.bredemeier@uk-essen.de
}

Keywords: circulating tumor cells, multimarker gene panel, metastatic breast cancer

Received: October 21, 2015

Accepted: April 16, 2016

Published: May 20, 2016

\section{ABSTRACT}

Background: Circulating tumor cells (CTC) are discussed to be an ideal surrogate marker for individualized treatment in metastatic breast cancer (MBC) since metastatic tissue is often difficult to obtain for repeated analysis. We established a nine gene qPCR panel to characterize the heterogeneous CTC population in MBC patients including epithelial CTC, their receptors (EPCAM, ERBB2, ERBB3, EGFR) CTC in Epithelial-Mesenchymal-Transition [(EMT); PIK3CA, AKT2), stem cell-like CTC (ALDH1) as well as resistant CTC (ERCC1, AURKA] to identify individual therapeutic targets.

Results: At TPO, at least one marker was detected in $84 \%$, at TP1 in $74 \%$ and at TP2 in 79\% of the patients, respectively. The expression of ERBB2, ERBB3 and ERCC1 alone or in combination with AURKA was significantly associated with therapy failure. ERBB2 + CTC were only detected in patients not receiving ERBB2 targeted therapies which correlated with no response. Furthermore, patients responding at TP2 had a significantly prolonged overall-survival than patients never responding $(p=0.0090)$.

Patients and Methods: $2 \times 5 \mathrm{ml}$ blood of 62 MBC patients was collected at the time of disease progression (TPO) and at two clinical staging time points (TP1 and TP2) after 8-12 weeks of chemo-, hormone or antibody therapy for the detection of CTC (AdnaTest EMT-2/StemCell Select ${ }^{\mathrm{TM}}$, QIAGEN Hannover GmbH, Germany). After pre-amplification, multiplex qPCR was performed. Establishment was performed using various cancer cell lines. PTPRC (Protein tyrosine phosphatase receptor type C) and GAPDH served as controls.

Conclusions: Monitoring MBC patients using a multimarker qPCR panel for the characterization of CTC might help to treat patients accordingly in the future.

\section{INTRODUCTION}

Circulating tumor cells (CTC) are suggested as potential surrogate markers for minimal residual disease, the precursor of metastatic disease. Their presence and persistence in blood has been associated with worse outcome in early and metastatic breast cancer (MBC) [1-13]. Furthermore, stem cell-like tumor cells as well as CTC undergoing Epithelial-Mesenchymal-Transition (EMT) have been identified within the population of CTC in these patients [11-20]. At present, there is no standard defined for the selection and detection of this highly heterogeneous population. Most methods require an enrichment step prior to detection, including density gradient centrifugation, and/ or positive/negative immunomagnetic procedures through antibodies specific for epithelial markers, such as the epithelial cell adhesion molecule (EPCAM) or leucocytes. New selection technologies include microfluidic devices, 
e.g. isolation of tumor cells by size using filters and the so called "CTC-Chips", using antibody-coated microspots. Subsequent characterization of CTC can be performed directly by using cytological approaches or indirectly, applying molecular methods and protein assays [21, 22]. Currently, the CellSearch system ${ }^{\circledR}$ (Veridex LLC) based on immunomagnetic EPCAM capturing is the only FDA approved system for CTC enumeration and the most frequently used one in the majority of the above mentioned clinical studies. However, the SWOG-S0500 trial showed no difference in the overall survival (OS) of patients with an increase in CTC counts during the course of therapy when either maintaining or changing therapy [23]. Despite the prognostic impact of CTC counts, characterization of CTC might complement these studies by improving the overall detection rate as well as sensitivity and thus permitting the assessment of potentially predictive molecular markers in CTC of MBC patients as already shown [24].

Molecular characterization of CTC is important not only to confirm their malignant origin but also to follow immuno-phenotypic changes with tumor progression and to identify diagnostically and therapeutically relevant targets which will help to select cancer patients for individual therapies. In this regard, ERBB2 as well as ER/ PR were shown to be differentially expressed between the primary tumor and corresponding metastases and/ or CTC and the expression status was shown to change during disease progression [25-32 ]. Furthermore, recently published studies demonstrated mutations in single CTC or bulk of CTC that changed during the course of disease [33-35].

Since metastatic tissue is often difficult to obtain, especially for repeated analysis, a comprehensive analysis of CTC would be appreciable to identify markers which reflect these changes and may allow physicians to tailor treatment accordingly. Most of the already published molecular methods, including ours, have analyzed a subset of genes, e.g. PIK3CA, AKT2, TWIST1, ALDH1, EPCAM, ERBB2, MUC1 and EGFR, respectively [14, 36-40]. Studies using a multimarker qPCR panel to follow up patients during the course of disease have rarely been published up to now [41].

Assuming that the heterogeneous group of CTC consists of epithelial, stem cell-like, EMT-like as well as CTC expressing resistance markers or therapeutic relevant receptors, we validated a qPCR multimarker gene panel [EPCAM, PIK3CA, AKT2, ERCC1, AURKA (Aurora Kinase A), ERBB2, ERBB3, EGFR, ALDH1] for the characterization of CTC in blood samples of MBC patients during palliative treatment. It was the purpose of the study to correlate these findings with response to therapy and to identify targets on CTC that may be able to improve treatment decisions.

\section{RESULTS}

\section{AdnaPanel Breast expression profile in healthy donors}

The raw data (ct-values) of 17 healthy donor (HD) profiles using the AdnaPanel Breast are summarized in Supplementary Figure 1. The ct-values shown for each gene represent the mean of 17 different HD samples. From these data, the cut-off values were calculated as ct mean-(1) $2 \times$ standard deviation and are displayed as grey squares in the graph. All genes were detected at a mean ct-value ranging from 25 to 32, except for the housekeeping gene GAPDH which was detected at lower ct values.

\section{Specificity determination of the target genes}

Applying the cut-off values generated within HD expression profiles (see above) in the calculation algorithm, the specificity was calculated for each gene as (1-N false positive/N all)*100. For ERBB2 and PIK3CA, a specificity of $100 \%$ was reached. Except for AURKA and EGFR, all specificities were about $90 \%$ and above $80 \%$ for AURKA and EGFR (Supplementary Figure 2)

\section{Influence of contaminating leucocytes}

Assuming that several genes of interest are not exclusively expressed in CTC but also to a certain amount in contaminating leucocytes (approximately 150 leucocytes per sample), a PTPRC (Protein tyrosine phosphatase receptor type $\mathrm{C}$, also known as CD45) normalizer was used to calculate the leucocyte contribution of each gene building up a $\Delta \Delta \mathrm{Ct}$. Leucocyte titration experiments showed that a growing number of leucocytes is linear to the expression intensity of PTPRC, resulting in a background signal dependent on the leucocyte amount in each sample (data not shown). Thus, the following calculation was performed: $\Delta \Delta \mathrm{Ct}\left(=\left(\mathrm{Cut}_{-\mathrm{off}}{ }_{\text {(gene) }}-\mathrm{Sample}\right)\right.$ $\mathrm{Ct}\left(_{\text {gene) }}-(\right.$ Cut-off $\mathrm{(PTPRC})-$ Sample Ct( $\left(_{(\text {PTPRC })}\right)$.

\section{Gene expression in cancer cell lines}

Ten or 20 cells of each cell line were spiked into the blood of HD and treated in the same way as described for patient samples. As shown in Supplementary Figure 3, the cell lines tested reflected the different CTC phenotypes. Among the various cell lines tested, the prostate cancer cell line LNCAP expressed most marker of interest and was used for further assay establishment Supplementary Figure 4. An artificial positive control was used for validation of ERCC1 expression and panel adjustment (Supplementary Figure 5). 


\section{Gene expression in $\mathrm{MBC}$ patients}

The study design is shown in Figure 1. In total, evaluation of CTC was feasible in 62 patients at TP0 and TP1 and in 56 patients at TP2, respectively. At TP0, at least one of the studied markers was detected in 52/62 (84\%) patients, at TP1 in 46/62 (74\%) patients and at TP2 in 44/56 (79\%) patients, respectively (data not shown). Interestingly, CTC negative patients at TP0 were mostly showing response to therapy. Among these patients, 17 were Overall Responders (OR), followed by nine Late Non-Responders (LNR) and seven Late Responders (LR) and two Overall Non-Responders (ONR). As apparent from Figure 2, gene expression was highly consistent across all time points. EPCAM was the most commonly expressed gene in $51 \%$ of all patient samples, followed by AURKA (43\%) and ERBB3 (30\%), respectively. ERBB2, EGFR and ALDH1 were expressed in $10 \%-20 \%$ of cases whereas the expression of ERCC1, AKT2 and PIK3CA was below $10 \%$.

\section{Prognostic relevance of the different genes}

Table 1 summarizes the prognostic significance of single genes as well as combinations at TP1 and TP2 with regard to response to therapy. In general, the expression of ERBB2 and ERBB3 alone or in combination with AURKA or EGFR was associated with therapy failure. In addition, ERCC1 alone or in combination with ERBB2 or AURKA was of prognostic significance as well as the combination of AURKA and EGFR ( $p$-values $<0.05$ ). All other genes, alone or in combination, showed no prognostic significance with regard to response at TP1 or TP2.

\section{Gene expression according to response groups}

As demonstrated in Figure 3A, 22 patients were classified as OR, 14 patients as ONR, seven patients as LR and 13 patients as LNR, respectively. When OR were compared with ONR, OR showed a consistent lower expression of the majority of marker genes across

\section{Therapy before start of investigation}



\section{- - Change of therapy}

Maintenance of therapy

Figure 1: Study design. Blood was collected at the time of disease progression (TP0) and at two consecutive clinical staging time points (TP1 and TP2). Patients were stratified according to response to therapy into Responder/Non-Responder at TP1 and in Overall-Responder (OR; Response at TP1 and TP2) and Overall-Non-Responder (ONR; No response at TP1 and TP2), as well as Late Responder (LR; No response at TP1, response at TP2) and Late Non-Responder (LNR; Response at TP1, no response at TP2) at TP2. 
Table 1: Prognostic relevance of the different genes analyzed

\begin{tabular}{l|l|l|}
\hline \multicolumn{1}{l}{ After therapy (TP1) } & \multicolumn{1}{l|}{ After therapy (TP2) } \\
\hline Genes detected in CTC & $\boldsymbol{p}$-value & $\boldsymbol{p}$-value \\
\hline EPCAM & 0,1955 & $\mathbf{0 , 0 3 3 0}$ \\
\hline ERCC1 & $\mathbf{0 , 0 0 8 2}$ & 0,2787 \\
\hline ERBB2 & $\mathbf{0 , 0 0 2 9}$ & $\mathbf{0 , 0 1 9 6}$ \\
\hline ERBB3 & $\mathbf{0 , 0 3 5 7}$ & $\mathbf{0 , 0 1 3 3}$ \\
\hline Combined gene expression & \multicolumn{2}{l|}{} \\
\hline ERBB3 + AURKA & 0,0814 & $\mathbf{0 , 0 1 4 5}$ \\
\hline ERBB2 + AURKA & $\mathbf{0 , 0 4 0 4}$ & $\mathbf{0 , 0 3 3 7}$ \\
\hline ERBB2 + ERCC1 & $\mathbf{0 , 0 2 2 6}$ & 0,1055 \\
\hline ERBB2 + EGFR & 0,1586 & $\mathbf{0 , 0 4 7 7}$ \\
\hline AURKA + ERCC1 & $\mathbf{0 , 0 2 2 6}$ & 0,2787 \\
\hline AURKA + EGFR & 0,9877 & $\mathbf{0 , 0 4 0 8}$ \\
\hline
\end{tabular}

The expression of some genes and gene combinations was significantly prognostic for having not responded to therapy at TP1 or TP2. Only significant $p$-values of genes/combinations are listed.

all time points (expression of $0 \%-30 \%$ ) except for EPCAM, AURKA, GAPDH... (expression in 30\%-50\%) (Figure 3B). In contrast, ONR showed enhanced gene expression already at TP0, predominately for EPCAM (70\%), AURKA (60\%) and ERBB3 (30\%), respectively. A continuous increase from TP0 to TP2 was observed for the expression of EPCAM, ERBB2 and ERBB3. Nearly $90 \%$ of ONR showed expression of EPCAM at TP2 and expression was significantly associated with not having responded to therapy $(p=0.0330)$ (Figure 3C). The greatest difference in gene expression between the OR and ONR group was observed for EPCAM, ERBB2, ERBB3 and AURKA. Especially for the ONR, a steady increase of EPCAM as well as ERBB2 and ERBB3 expression was observed in comparison to the OR group (Figure 4).

\section{Correlation of gene expression with outcome}

The OS was calculated as the period of time from the date of sample drawing (TP0) until the date of death. For OS analysis, only OR and ONR were compared. The median OS was 27 months for OR [ $n=22,10$ to 30 months] vs. 18 months for ONR [ $n=14,5$ to 27 months]. As shown in Figure 5, OR had a significantly longer OS than ONR $(p=0.0090)$. As apparent from Table 2, the negative prognostic effect at TP1 seemed to be mostly related to the expression of ERCC1 $(p=0.0031)$ alone or in combination with $\operatorname{ERBB} 2(p=0.0293)$ or $\operatorname{ERBB} 3(p=0.0084)$ or AURKA $(p=0.0094)$ as well as to the expression of EGFR alone ( $p=0.0084)$, or in combination with ERBB3 ( $p=0.0084)$ or AURKA $(p=0.0084)$. For responders, no significant single genes or combinations could be identified.

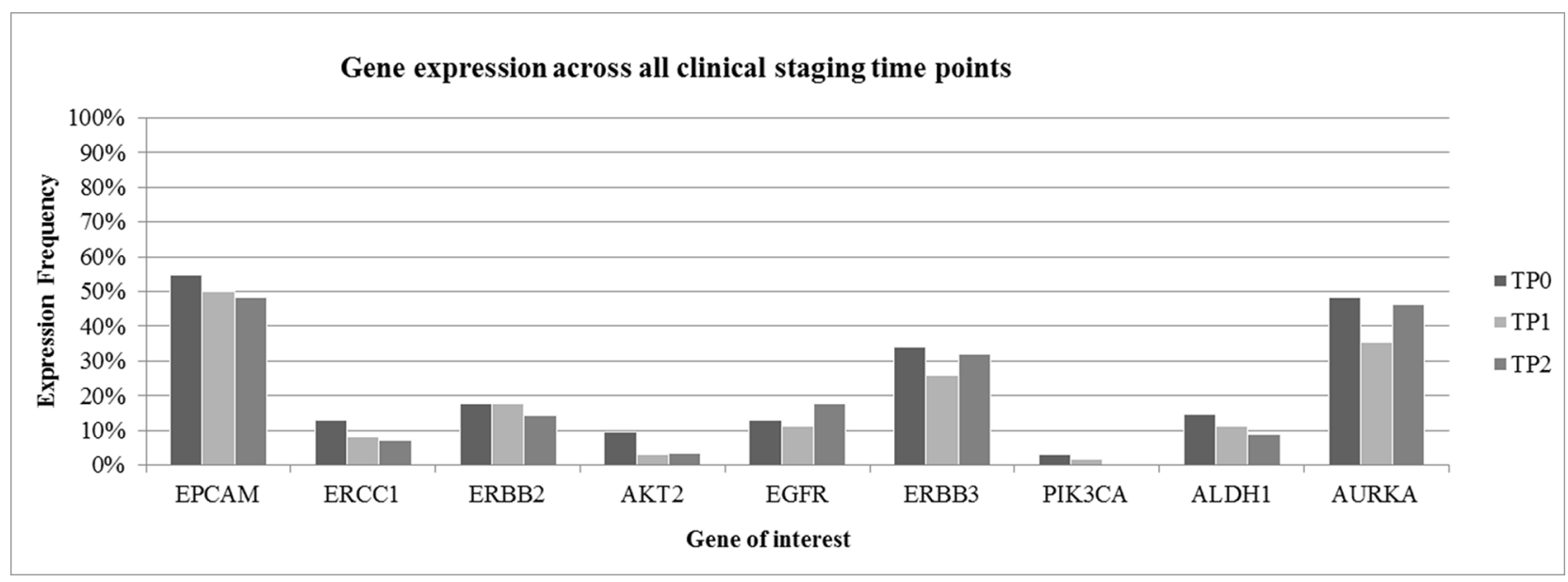

Figure 2: Gene expression across all clinical staging time points. Gene expression pattern was highly consistent across all clinical staging time points. EPCAM, AURKA and ERBB3 were the most commonly expressed genes. Clinical outcome was not taken into consideration to get a general overview of gene expression in patient samples. 
Table 2: Genes associated with reduced OS at TP1

\begin{tabular}{|c|c|c|c|}
\hline Gene expression in Non-Responders at TP1 & $p$-value & Hazard ratio & $95 \%$ CI of ratio \\
\hline ERCC1 & 0,0031 & 0.04723 & 0.006212 to 0.3591 \\
\hline EGFR & 0,0084 & 0.01274 & 0.0004959 to 0.3274 \\
\hline ERCC1 + ERBB2 & 0,0293 & 0.4091 & 0.1590 to 0.6592 \\
\hline ERCC1 + ERBB3 & 0,0084 & 0.2727 & 0.06499 to 0.4805 \\
\hline ERCC1 + AURKA & 0,0094 & 0.3636 & 0.1135 to 0.6137 \\
\hline EGFR + AURKA & 0,0084 & 0.2727 & 0.06499 to 0.04805 \\
\hline EGFR + ERBB3 & 0,0084 & 0.2727 & 0.06499 to 0.04805 \\
\hline
\end{tabular}

The genes and gene combinations listed were significantly associated with a shorter OS. For Responders, no significant single gene or combinations could be identified.

\section{Influence of targeted therapies on CTC}

ERBB2 was one of the genes mostly associated with worse outcome. Since 17 patients received ERBB2 targeted therapies during the course of the disease, we evaluated ERBB2 expression in CTC with regard to response to ERBB2 targeted therapy. As apparent from Figure 6, in patients under ERBB2 targeted therapy, no ERBB2 positive CTC were detected, irrespective of the response class. In contrast, in patients not receiving ERBB2 targeted therapy, ERBB2 positive CTC were frequently detected in all response groups except for most of the OR.

\section{DISCUSSION}

\section{Key findings}

In this study, we have established a multimarker qPCR panel to characterize the heterogeneous CTC population to monitor palliative treatment of MBC patients. The most commonly expressed gene was EPCAM, followed by AURKA. Mainly ERBB2/ERBB3 positive CTC as well as CTC expressing the resistance marker AURKA and ERCC1 were associated with worse outcome. In addition, ERBB2 positive CTC were only expressed in patients not receiving ERBB2 targeted therapy.
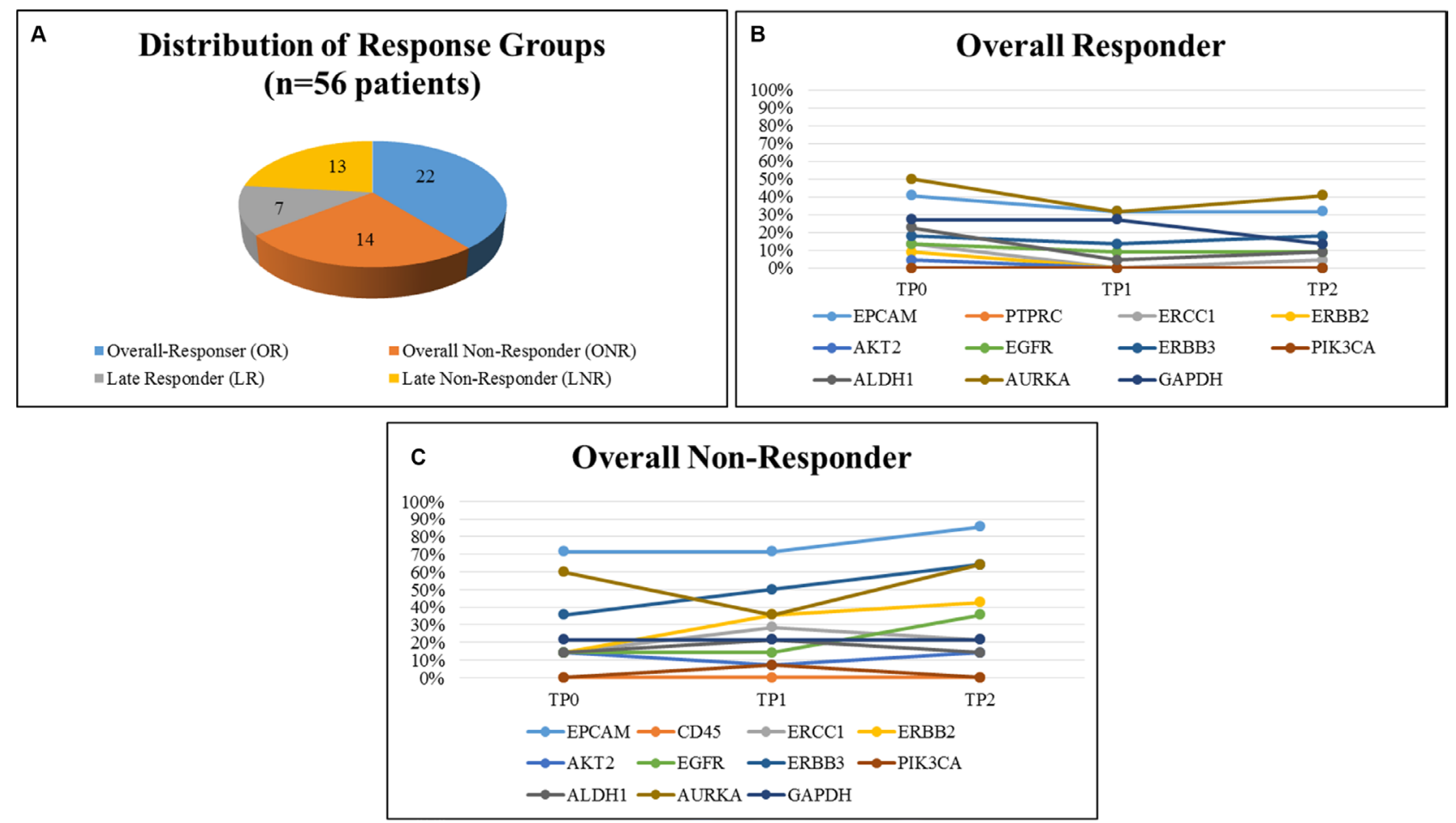

Figure 3: Distribution of response groups and comparison of gene expression in OR and ONR. 56 Patients could be evaluated for this analysis and were stratified into 22 OR, 14 ONR, 7 LR and 13 LNR, respectively (A). OR showed a consistent low expression of our marker genes, except for AURKA and EPCAM (B), in comparison to ONR showing higher gene expression levels at all time points $(\mathbf{C})$. 


\section{Gene expression}

Up to now, a variety of groups have been characterizing CTC on the molecular as well as on the cellular level, mostly the expression of single marker genes, only a few studies have been investigating multi marker gene panel. The comparison of ERBB2 expression on CTC and tumor tissue resulted in an overall concordance of $74 \%$ and $89 \%$ when comparing CTC with the primary tumor and $69 \%$ when compared to metastases, respectively [29, 45].

Assessing six genes in 64 operable $\mathrm{BC}$ and $20 \mathrm{MBC}$ patients as well as in $17 \mathrm{HD}$, Markou et al. detected CK19, ERBB2, MAGEA3, SCGB2A2 and TWISTP1 in 26.6\%, $12.5 \%, 18.7 \%, 10.9 \%$ and $31.2 \%$ cases, respectively [46]. An EMT-like as well as stem cell-like CTC phenotype has also been described in other studies. In this regard, using qPCR for the expression of EMT transcription factors, Mego et al., showed that patients with a high percentage of CD326+ or EMT transcription factor overexpressing cells had a shorter progression-free survival [47]. In addition, the EMT transcription factors TWISTP1, SNAIL1, ZEB1, TG2 and the stemness marker ALDH1, CD24, CD44 and CD133 were shown to be present in the CD326-PTPRCfraction of ERBB2+ MBC patients [10]. Comparable data were also published by others applying confocal laser scanning microscopy for the detection of phosphorylated (phospho) PIK3CA, phospho-EGFR, phospho-AKT and/or ERBB2 in early and MBC patients $[36,48]$. "With regard to PIK3CA, hotspot mutations..." were frequently detected in CTC of operable $\mathrm{BC}$ and $\mathrm{MBC}$ patients which changed during tumor progression resulting in a worse outcome [35]. Using singleplex and multiplex qPCR, our group has already shown that the expression of at least one EMT marker (PIK3CA, AKT2, TWIST1) and/or the expression of ALDH1 might serve as an indicator for therapy resistance resulting in a poor prognosis in $\mathrm{MBC}$ patients [14]. However, analyzing CTC more comprehensively, it seems as if the expression of epithelial CTC, resistant CTC, as well as ERBB2 and/or ERBB3 and/or EGFR positive cells seem to be more associated with worse outcome, especially in ONR. This might have different reasons. On the one hand, these findings are in accordance with other studies, showing that feedback mechanisms caused by intervention in the PIK3CA/AKT2 pathway can lead to rebounded ERBB3 activity and hence, therapy resistance [49-52]. On the other hand, the individual therapies might have eradicated stem cell-like CTC as already shown for trastuzumab, lapatinib and everolimus [53-55]. Furthermore, CTC that have undergone EMT might have performed a switch back to epithelial CTC.

A variety of studies have already shown the prognostic impact of CTC as well as their function of monitoring disease progression [1-13, 56, 57]. However, the SWOG-S0500 trial, changing therapy of MBC patients versus maintaining the therapy with regard to changes in CTC counts during follow-up assessment, showed no difference in OS of patients with an increase in CTC



Figure 4: Most differently expressed genes in OR versus ONR. EPCAM was expressed in up to 90\% of all ONR. Furthermore, great differences in gene expression in OR versus ONR were observed for ERBB2, ERBB3 and AURKA. 


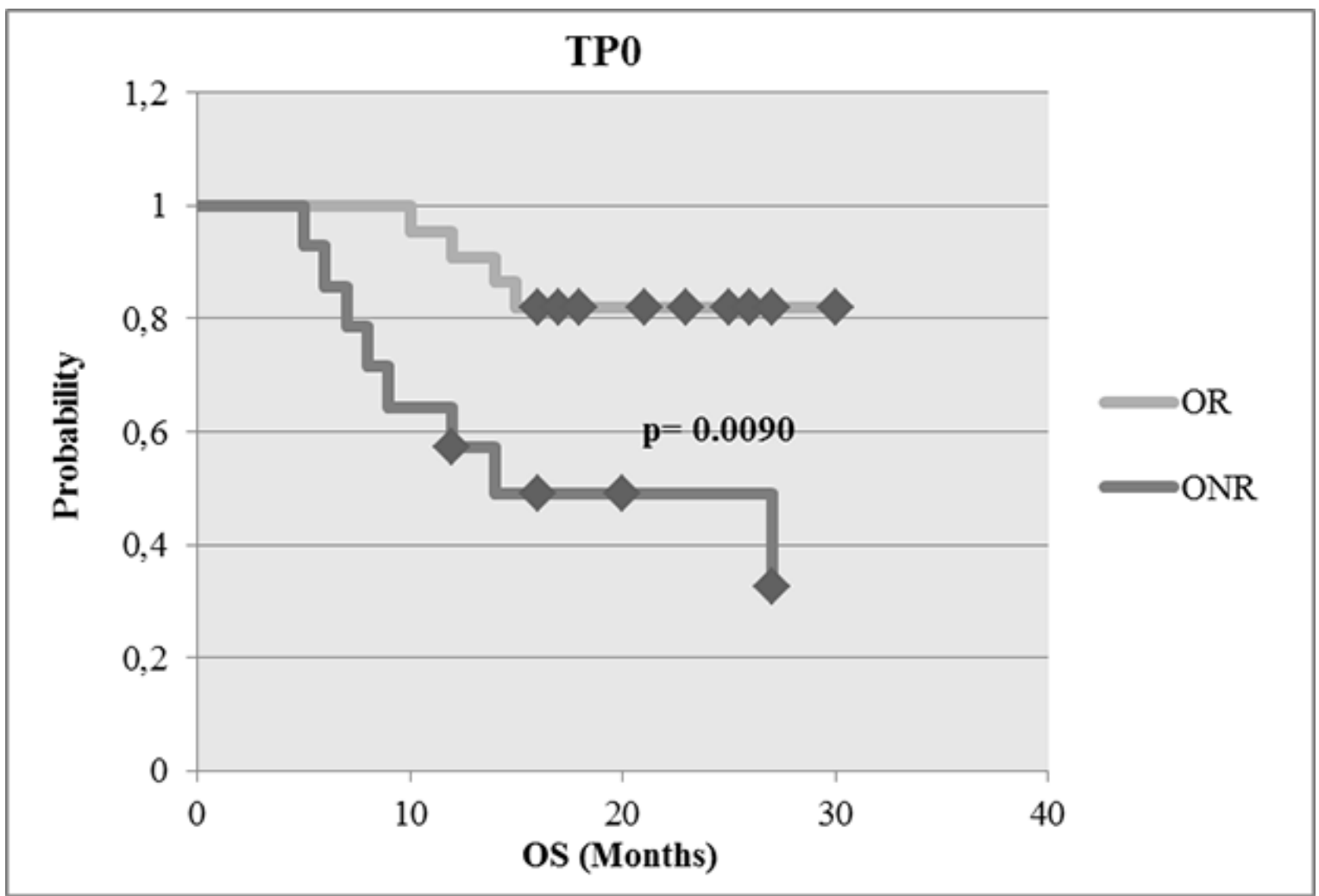

Figure 5: Survival analysis of OR compared with ONR. OR had a significant longer OS than ONR at the time point tested $(p=0.0090)$.

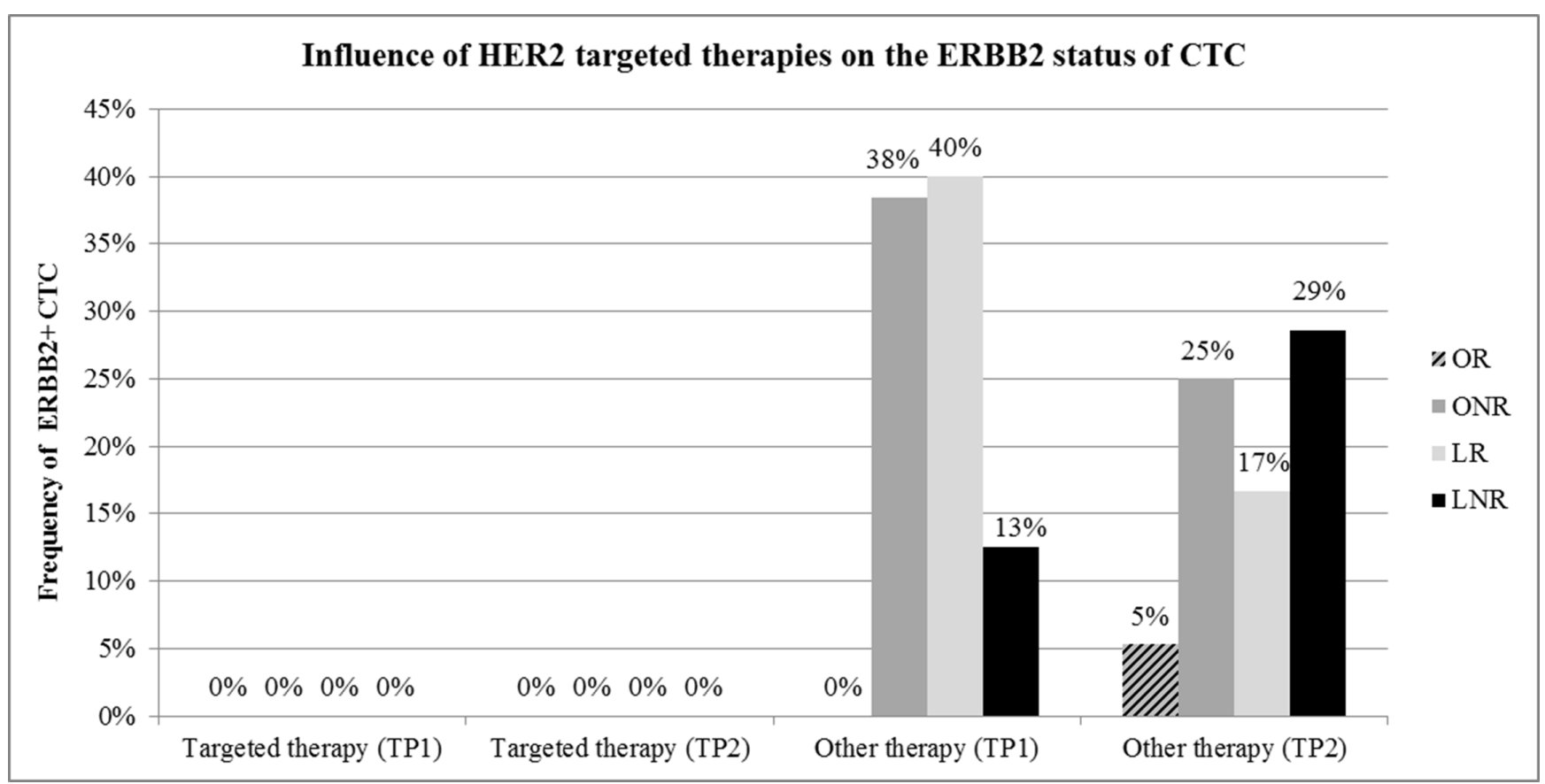

Figure 6: Influence of ERBB2 targeted therapies on the ERBB2 status of CTC. No ERBB2 positive CTC (ERBB2+) were detected in patients under ERBB2 targeted treatment at TP1 and TP2. This finding was independent of the response class. ERBB2+ CTC were frequently detected in patients receiving other than targeted therapies, mainly in patients not responding to treatment. 
counts during course of therapy when either maintaining or changing therapy [23]. Thus, new strategies to target CTC are investigated in clinical studies. The DETECT III study was directed at initial ERBB2- MBC patients with ERBB2+ CTC, investigating the effect of ERBB2 targeted therapy with lapatinib plus standard treatment (ClinicalTrials.gov Identifier: NCT01619111). The succession study DETECT IV was designed for patients with hormone receptor positive but ERBB2- MBC, having ERBB2- CTC. This study is investigating the effect of everolimus in combination with standard treatment on CTC (ClinicalTrials.gov Identifier: NCT02035813).

Despite the prognostic impact of CTC counts, comprehensive molecular profiling might complement these studies by improving the specificity and, thus, permitting the assessment of genomic markers in CTC of MBC patients. In this regard, Mostert et al. developed a 16 gene profile assay based on qPCR mRNA expression quantification, distinguishing patients showing no response to therapy or dying in less than nine months after start of first-line systemic therapy from those with a better prognosis [58]. Moreover, Fina et al. compared CTC counts with gene expression patterns based on the PAM50 gene panel in CTC from seven MBC patients resulting in no correlation between CTC number and gene expression levels as well as molecular subtype specific differences [41].

Monitoring CTC over a period of time seems necessary since marker profiles can change during course of a therapy and during disease progression as already shown for ERBB2, ER and PR [27, 32, 59]. For ERBB2, several studies indicated that ERBB2+ MBC patients have EMT-like CTC and that ERBB2 seems to be selectively expressed in cancer stem cells of initially ER+ and ERBB2negative luminal $\mathrm{BC}[10,55]$. There is growing evidence that patients with an ERBB2-negative primary tumor could also benefit from a trastuzumab treatment if ERBB2+ CTC can be detected [30, 60-61]. This is in accordance with our study showing that ERBB2+ cells were only found in patients not receiving ERBB2 targeted treatment whereas patients under an ERBB2 targeted therapy had no ERBB2+ CTC. Very recently, Kallergi et al. showed that the expression of truncated ERBB2 (p95ERBB2) on CTC of $\mathrm{BC}$ patients, was associated with a poor prognosis and resistance to trastuzumab therapy [62].

Moreover, the expression of ERBB2 and ERBB3 alone or in combination with resistance markers seem to promote uncontrolled tumor cell growth in overt metastases, leading to a shorter OS. Several studies are currently investigating the effect of combining ERBB2 and/or ERBB3 treatment with conventional therapy. As an example, the PERUSE study is evaluating the treatment of $\mathrm{MBC}$ or locally advanced $\mathrm{BC}$ patients with pertuzumab in combination with trastuzumab and taxane in first-line (ClinicalTrials.gov Identifier: NCT01572038). Similarly the CLEOPATRA study is investigating the improvement in the OS of ERBB2+ MBC patients when treated with a combination of pertuzumab, trastuzumab and chemotherapy with docetaxel (ClinicalTrials.gov Identifier NCT00567190).

We were also able to show that EGFR was frequently expressed in CTC of non-responders which was associated with a shorter OS whereas the expression of AURKA was associated with a shorter OS when comparing OR with ONR. With regard to AURKA, these results are in alignment with the results of Zhang et al. who demonstrated that AURKA expression was significantly associated with a shorter OS by systematic review and meta-analysis in various solid tumors. For BC exclusively, the AURKA expression levels were not significantly associated with poor prognosis but patients receiving the AURKA inhibitor alisertib in a phase II study, showed significant response [63].

EGFR and downstream pathways were shown to be implicated in the regulation of EMT and invasion and EGFR overexpression has been observed across all BC subtypes [64-70]. Tyrosinkinase inhibitors were shown to inhibit invasion and cell motility by transforming mesenchymal cells to an epithelial phenotype and thus might be acting through inhibition of EMT in vitro [71]. However, results of clinical studies have often been disappointing probably due to the fact that patients were not selected on the basis of EGFR expression and had a long therapy history $[72,73]$.

\section{MATERIALS AND METHODS}

\section{Patient population and characteristics}

The study was conducted at the Department of Gynecology and Obstetrics in collaboration with the Department of Internal Medicine (Cancer Research) at the University Hospital Essen. In total, 180 samples of 62 MBC patients have been studied from November 2013 until May 2015.

\section{Eligibility criteria}

The eligibility criteria were as follows: age $\geq 18$ years; measurable or evaluable $\mathrm{MBC}$; predicted life expectancy $\geq 2$ months; Eastern Cooperative Oncology Group (ECOG) scores for performance status of $0-2$; no severe uncontrolled co-morbidities or medical conditions; no second malignancies. Patients had either a relapse of breast cancer diagnosed years before and were to start chemotherapy or a documented progressive $\mathrm{BC}$ before receiving a new endocrine, chemo- or experimental therapy. Prior adjuvant treatment, radiation or any other treatment of metastatic disease were permitted. Exclusion criteria were other malignancies except breast cancer. All specimens were obtained after written informed consent and collected using protocols approved by the institutional review board (05/2856). 


\section{Response criteria}

Before starting a new treatment, patients underwent an evaluation of metastatic sites by ultrasound, $\mathrm{x}$-ray or computer tomography. Re-evaluations of disease status were done by the same techniques every 8-12 weeks, depending on the treatment schedule, until the loss or death of a patient. Response to therapy was evaluated according to the Response Evaluation Criteria in Solid Tumors (RECIST). Complete Response (CR): disappearance of all target lesions; Partial Response (PR): at least $30 \%$ decrease in the sum of the LD (longest diameter) of target lesions, taking as reference the baseline sum LD; Progressive Disease (PD): at least $20 \%$ increase in the sum of the LD target lesions, taking as reference the smallest sum LD recorded since the treatment started or the appearance of one or more new lesions; Stable Disease (SD): neither sufficient shrinkage to qualify for PR nor sufficient increase to qualify for $\mathrm{PD}$, taking as reference the smallest sum LD since the treatment started.

\section{Study design}

$2 \times 5 \mathrm{ml}$ blood of $62 \mathrm{MBC}$ patients was collected at three different time points for the evaluation of CTC (Figure 1). TP0: new metastasis of the disease or progressive disease under a given therapy; TP1: 8-12 weeks after chemo-, hormone or antibody therapy; TP2: after further 8-12 weeks of therapy.

\section{Stratification of patients}

Patients were stratified as follows: (1) Overall Responder (OR, response to therapy at TP1 and TP2), (2) Overall Non-Responder (ONR, no response to therapy at TP1 and TP2), (3) Late Responder (LR, response to therapy at TP2 but not at TP1) and (4) Late NonResponder (LNR, response to therapy at TP1 but not at TP2), respectively. According to RECIST criteria, patients with SD, CR or PR were classified as Responders to therapy whereas patients with PD were Non-Responders.

\section{Immunohistochemical analysis}

For each of the 62 patients, the tumor type, TNMstaging and grading were assessed according to the WHO-classification of tumors of the breast [74] and the sixth edition of the TNM Classification System [75]. The estrogen (ER) and the progesterone (PR) receptor status were determined by immunohistochemistry. The DAKO-score for the expression of ERBB2 was re-evaluated with the HercepTest ${ }^{\circledR}$ (Dako). FISH analysis in cases of $2+$ staining as determined with the HercepTest ${ }^{\mathbb{B}}$ was performed as described elsewhere [76].

\section{Assay establishment in cell culture experiments}

The multimarker gene panel for CTC characterization was established using cell lines of different tumor entities since not all genes of interest were expressed uniquely in one cell line. 20 cells of LNCAP (prostate), PC3 (prostate), HTP1197 (bladder), RT4 (urinary bladder) and Ovcar3 (ovarian) as well as 10 cells of the breast cancer cell lines MDAMB231, T47D, SKBR3 and MCF- 7 were spiked into blood of healthy donors (HD, $n=17)$ and processed as described below. Among the various cell lines tested, the prostate cell line LNCAP expressed most marker of interest and was used for further assay validation. Since ERCC1 was not expressed by the cell lines tested, an artificial positive control was used for establishment (Supplementary Figures 3, 4 and 5). The cell lines were purchased from the ATCC (American Tissue Culture Collection, Rockville, MD) and cultured in a humidified incubator at $37^{\circ} \mathrm{C}$ in an atmosphere of $5 \% \mathrm{CO}_{2}$ and $95 \%$ air. The cell lines were maintained in RPMI medium supplemented with $10 \%$ heat-inactivated fetal bovine serum and 1\% penicillin/ streptomycin (Biochrom KG, Seromed, Berlin, Germany). Amplicon sizes and references of the target genes are shown in Supplementary Table 1.

\section{Sampling of blood}

At each time point, $2 \times 5 \mathrm{ml}$ EDTA blood was collected for CTC isolation. All "in-house samples" were collected in S-Monovettes ${ }^{\circledR}$ (Sarstedt AG \& Co., Nümbrecht, Germany) whereas "overnight samples" were collected in AdnaCollect tubes (QIAGEN Hannover $\mathrm{GmbH}$, Langenhagen, Germany). As proven by the manufacturer, this did not affect the final results. The samples were stored at $4^{\circ} \mathrm{C}$ until further examination and were processed immediately or not later than four hours after blood withdrawal (24 hours for overnight samples).

\section{Enrichment of CTC}

Blood samples were analyzed for CTC using the AdnaTest EMT-2/StemCellSelect ${ }^{\mathrm{TM}}$ (QIAGEN Hannover $\mathrm{GmbH}$, Langenhagen, Germany) that enriches CTC via antibody coated magnetic beads, targeting EPCAM, EGFR and ERBB2. The AdnaTest EMT-2/StemCell antibody setup has proven better sensitivity over the AdnaTest BreastCancer setup (data not shown). Labelled CTC were extracted using a magnetic particle concentrator according to the manufacturer's instructions (130122 EN) and were subsequently lysed. The cell lysate was stored for a maximum of two weeks at $-80^{\circ} \mathrm{C}$ until further processing.

\section{Detection of CTC}

mRNA was isolated from the cell lysate of pre-enriched tumor cells using the AdnaTest EMT-2/StemCellDetect ${ }^{\mathrm{TM}}$ 
(QIAGEN Hannover GmbH, Langenhagen, Germany) which is based on oligo(dt)25 coated magnetic beads. Reverse transcription was performed using the Sensiscript Reverse Transcription Kit ${ }^{\mathrm{TM}}$ (QIAGEN, Hilden, Germany). cDNA was gene specifically pre-amplified using the TATAA Multiplex Grand Master Mix according to in-house designed assays. PCR activation was performed at $95^{\circ} \mathrm{C}$ for 3 minutes and followed by 16 cycles of denaturation at $95^{\circ} \mathrm{C}$ for 20 seconds, extension for 20 seconds at $60^{\circ} \mathrm{C}$ and elongation at $72^{\circ} \mathrm{C}$ for 3 minutes, respectively. Multiplex qPCR was performed for the following nine markers: EPCAM (epithelial); PIK3CA, AKT2 (EMT); ALDH1 (stem cell); ERCC1, AURKA (resistance markers); ERBB2, ERBB3, EGFR (receptors); PTPRC (Protein tyrosine phosphatase receptor type C, leucocyte control) and GAPDH (housekeeping gene) as well as the synthetic EPCAM fragment as an internal reference using iTaq Universal Supermix SYBR Green Mix ${ }^{\mathrm{TM}}$ (Biorad, Hercules, CA, USA). qPCR was performed using the StepOnePlus ${ }^{\mathrm{TM}}$ (Life Technologies, Carlsbad, CA, USA) real time system. After PCR activation at $95^{\circ} \mathrm{C}$ for 3 minutes, the thermal profile of 35 cycles in total was as follows: 20 seconds at $95^{\circ} \mathrm{C}$, 20 seconds at $60^{\circ} \mathrm{C}, 30$ seconds at $72^{\circ} \mathrm{C}$ and 1 minute at $95^{\circ} \mathrm{C}$. Additionally, melting curves were performed. Remark: The establishment process and the measurement of $\mathrm{HD}$ samples were performed with 40 cycles of qPCR. Since 35 cycles were sufficient after cut-off determination, all patient samples were measured with a shorter cycle setup.

\section{Data evaluation and statistical analysis}

Assuming that several genes of interest are not exclusively expressed in CTC, but also in contaminating leucocytes, a PTPRC normalizer was included to calculate the leucocyte contribution for each gene. In leucocyte titration experiments, we found a linear correlation of the leucocyte number and the PTPRC Ct-value as well as a linear contribution to each genes Ct-value depending on the leucocyte number (data not shown). A cut-off value was calculated for each gene separately in a way that the false positive rate in all $\operatorname{HD}(n=17)$ was lower than $10 \%$ (specificity $>90 \%$, except for AURKA: specificity $>80 \%$ ). If there were additional melting peaks or melting peaks at the wrong temperature, the $\mathrm{Ct}$-values were excluded. Furthermore, results were not normalized using GAPDH cq values but were corrected for PTPRC. GAPDH expression is resulting from the number of contaminating leucocytes remaining after CTC enrichment. Subsequently, delta delta $\mathrm{Ct}$ was calculated as $\Delta \Delta \mathrm{Ct}=\left(\right.$ Cut-off ${ }_{\text {(gene) }}-$ Sample Ct $\left.\mathrm{t}_{\text {(gene) }}\right)-\left(\right.$ Cut-off $_{(\text {PTPRC) }}$-Sample $\left.\mathrm{Ct}_{\text {(PTPRC) }}\right)$.

\section{CONCLUSIONS}

Using a multimarker qPCR panel for comprehensive molecular characterization of CTC, we here demonstrate that changes in the molecular profile of CTC in the course of therapeutic interventions can determine response to the applied therapy. Since metastatic tissue is often difficult to obtain, CTC may have the potential to serve as liquid biopsy for better therapy guidance. Further investigations will include more genes to get deeper insights into the heterogeneity of CTC during the course of disease.

\section{ACKNOWLEDGMENTS AND FUNDING}

We gratefully thank the patients for their willingness to participate in the study. The authors highly valuate the assistance of Julia Scholz from the Department of Internal Medicine (Cancer Research) for organizational functions, clinical documentation, blood drawing and the medical and nursing team of the Department of Gynecology and Obstetrics for their collaboration in sample collection and preparatory operation-thank you for your contribution to scientific work.

\section{CONFLICTS OF INTEREST}

The corresponding author is an employee at the University Hospital Essen and has no conflict of interest to disclose.

\section{REFERENCES}

1. Cristofanilli M, Budd GT, Ellis MJ, Stopeck A, Matera J, Miller MC, Reuben JM, Doyle GV, Allard WJ, Terstappen LW, Hayes DF. Circulating tumor cells, disease progression, and survival in metastatic breast cancer. N Engl J of Med. 2004; 351:781-91.

2. Smerage JB, Hayes DF. The prognostic implications of circulating tumor cells in patients with breast cancer. Cancer Invest. 2008; 26:109-14.

3. Xenidis N, Perraki M, Kafousi M, Apostolaki S, , Bolonaki I, Stathopoulou A, Kalbakis K, Androulakis N, Kouroussis C, Pallis T, Christophylakis C, Argyraki K, Lianidou ES, et al. Predictive and prognostic value of peripheral blood cytokeratin-19 mRNApositive cells detected by real-time polymerase chain reaction in node-negative breast cancer patients. J Clin Oncol. 2006; 24:3756-62.

4. Xenidis N, Ignatiadis M, Apostolaki S, Perraki M, Kalbakis K, Agelaki S, Stathopoulos EN, Chlouverakis G, Lianidou E, Kakolyris S, Georgoulias V, Mavroudis D. Cytokeratin-19 mRNA-positive circulating tumor cells after adjuvant chemotherapy in patients with early breast cancer. J Clin Oncol. 2009; 27:2177-84.

5. Ramirez JM, Fehm T, Orsini M, Cayrefourcq L, Maudelonde T, Pantel K, Alix-Panabières C. Prognostic relevance of viable circulating tumor cells detected by EPISPOT in metastatic breast cancer patients. Clin Chem. 2014; 60:214-21. 
6. Tewes M, Aktas B, Welt A, Mueller S, Hauch S, Kimmig R, Kasimir-Bauer S. Molecular profiling and predictive value of circulating tumor cells in patients with metastatic breast cancer: an option for monitoring response to breast cancer related therapies. Breast Cancer Res Treat. 2009; 115:581-90.

7. Saloustros E, Perraki M, Apostolaki S, Kallergi G, Xyrafras A, Kalbakis K, Agelaki S, Kalykaki A, Georgoulias V, Mavroudis D. Cytokeratin-19 mRNA-positive circulating tumor cells during follow-up of patients with operable breast cancer: prognostic relevance for late relapse. Breast Cancer Res. 2011; 13:R60.

8. Pierga JY, Hajage D, Bachelot T, Delaloge S, Brain E, Campone M, Diéras V, Rolland E, Mignot L, Mathiot C, Bidard FC. High independent prognostic and predictive value of circulating tumor cells compared with serum tumor markers in a large prospective trial in first-line chemotherapy for metastatic breast cancer patients. Ann Oncol. 2012; 23:618-24.

9. Lucci A, Hall CS, Lodhi AK, Bhattacharyya A, Anderson AE, Xiao L, Bedrosian I, Kuerer HM, Krishnamurthy S. Circulating tumor cells in non-metastatic breast cancer: a prospective study. Lancet Oncol. 2012; 13:688-95.

10. Giordano A, Gao H, Anfossi S, Cohen E, Mego M, Lee BN, Tin S, De Laurentis M, Parker CA, Alvarez RH, Valero V, Ueno NT, De Placido S, et al. Epithelial-mesenchymal transition and stem cell markers in patients with HER2positive metastatic breast cancer. Mol Cancer Ther. 2012; 11:2526-34.

11. Wallwiener M, HartkopfAD, Baccelli I, Riethdorf S, Schott S, Pantel K, Marmé F, Sohn C, Trumpp A, Rack B, Aktas B, Solomayer EF, Müller V, et al. The prognostic impact of circulating tumor cells in subtypes of metastatic breast cancer. Breast Cancer Res Treat. 2013; 137:503-10.

12. Bidard FC, Peeters DJ, Fehm T, Nole F, Gisbert-Criado R, Mavroudis D. Clinical validity of circulating tumor cells in patients with metastatic breast cancer: a pooled analysis of individual patients. Lancet Oncol. 2014; 15:406-14.

13. Rack B, Schindlbeck C, Jueckstock J, Andergassen U, Hepp P, Zwingers T, Friedl TW, Lorenz R, Tesch H, Fasching PA, Fehm T, Schneeweiss A, Lichtenegger W, et al. SUCCESS Study Group. Circulating tumor cells predict survival in early average-to-high risk breast cancer patients. J Natl Cancer Inst. 2014; 15:106dju066.

14. Aktas B, Tewes M, Fehm T, Hauch S, Kimmig R, KasimirBauer S. Stem cell and epithelial-mesenchymal transition markers are frequently overexpressed in circulating tumor cells of metastatic breast cancer patients. Breast Cancer Res. 2009; 11:R46.

15. Theodoropoulos PA, Polioudaki H, Agelaki S, Kalergi G, Saridaki Z, Mavroudis D, Georgoulias V. Circulating tumor cells with a putative stem cell phenotype in peripheral blood of patients with breast cancer. Cancer Lett. 2010; 288:99-106.

16. Mego M, Mani SA, Cristofanilli M. Molecular mechanisms of metastasis in breast cancer-clinical applications. Nat Rev Clin Oncol. 2010; 7:693-701.
17. Kallergi G, Papadaki MA, Politaki E, Mavroudis D, Georgoulias V, Agelaki S. Epithelial to mesenchymal transition markers expressed in circulating tumour cells of early and metastatic breast cancer patients. Breast Cancer Res. 2011; 13:R59.

18. Kasimir-Bauer S, Hoffmann O, Wallwiener D, Kimmig R, Fehm T. Expression of stem cell and epithelialmesenchymal transition markers in primary breast cancer patients with circulating tumor cells. Breast Cancer Res. 2012; 14:R15.

19. Papadaki MA, Kallergi G, Zafeiriou Z, Manouras L, Theodoropoulos PA, Mavroudis D, Georgoulias V, Agelaki S. Co-expression of putative stemness and epithelial-tomesenchymal transition markers on single circulating tumour cells from patients with early and metastatic breast cancer. BMC Cancer. 2014; 14:651.

20. Krawczyk N, Meier-Stiegen F, Banys M, Neubauer H, Ruckhaeberle E, Fehm T. Expression of stem cell and epithelial-mesenchymal transition markers in circulating tumor cells of breast cancer patients. Biomed Res Int. 2014; 415721.

21. Lianidou E, Markou A. Circulating tumor cells in breast cancer: detection systems, molecular characterization, and future challenges. Clin Chem. 2011; 57:1242-55.

22. Alix-Panabières $\mathrm{C}$, Pantel $\mathrm{K}$. Challenges in circulating tumour cell research. Nat Rev Cancer. 2014; 14:623-31.

23. Smerage JB, Barlow WE, Hortobagyi GN, Winer EP, Leyland-Jones B, Srkalovic G, Tejwani S, Schott AF, O'Rourke MA, Lew DL, Doyle GV, Gralow JR, Livingston RB, et al. Circulating Tumor Cells and Response to Chemotherapy in Metastatic Breast Cancer: SWOG S0500. J Clin Oncol. 2014; 32: 3483-9.

24. Andreopoulou E, Yang LY, Rangel KM, Reuben JM, Hsu L, Krishnamurthy S, Valero V. Comparison of assay methods for detection of circulating tumor cells in metastatic breast cancer: AdnaGen AdnaTest BreastCancer Select/DetectTM versus Veridex CellSearchTM system. Int J Cancer. 2011; 130:1590-7.

25. Hayes DF, Walker TM, Singh, Vitetta ES, Uhr JW, Gross S, Rao C, Doyle GV, Terstappen LW. Monitoring expression of HER-2 on circulating epithelial cells in patients with advanced breast cancer. Int J Oncol. 2002; 21:1111-7.

26. Fehm T, Hoffmann O, Aktas B, Becker S, Solomayer EF, Wallwiener D, Kimmig R, Kasimir-Bauer S: Detection and characterization of circulating tumor cells in blood of primary breast cancer patients by RT-PCR and comparison to status of bone marrow disseminated cells. Breast Cancer Res. 2009; 11:R59.

27. Fehm T, Mueller V, Aktas B, Janni W, Schneeweiss A, Stickeler E, Lattrich C, Löhberg CR, Solomayer E, Rack B, Riethdorf S, Klein C, Schindlbeck C, et al. HER2 status of circulating tumor cells in patients with metastatic breast cancer: a prospective, multicenter trial. Breast Cancer Res Treat. 2010; 124:403-12. 
28. Riethdorf S, Mueller V, Zhang L, Rau T, Loibl S, Komor M, Roller M, Huober J, Fehm T, Schrader I, Hilfrich J, Holms F, Tesch $\mathrm{H}$, et al. Detection and HER2 expression of circulating tumor cells: prospective monitoring in breast cancer patients treated in the neoadjuvant GeparQuattro trial. Clin Cancer Res. 2010; 16:2634-45.

29. Punnoose EA, Atwal SK, Spoerke JM, Savage H, Pandita A, Yeh RF, Pirzkall A, Fine BM, Amler LC, Chen DS, Lackner MR. Molecular biomarker analyses using circulating tumor cells. PLoS One. 2010; 5e12517.

30. Ignatidis M, Rothe F, Chaboteaux C, Durbecq V, Rouas G, Criscitiello C, Metallo J, Kheddoumi N, Singhal SK, Michiels S, Veys I, Rossari J, Larsimont D, et al. HER2positive circulating tumor cells in breast cancer. PLoS One. 2011; 6:e15624.

31. Sieuwerts AM, Mostert B, Bolt-de Vries J, Peeters D, de Jongh FE, Stouthard JM, Dirix LY, van Dam PA, Van Galen A, de Weerd V, Kraan J, van der Spoel P, RamírezMoreno R, et al. mRNA and microRNA expression profiles in circulating tumor cells and primary tumors of metastatic breast cancer patients. Clin Cancer Res. 2011; 17:3600-18.

32. Aktas B, Mueller V, Tewes M, Zeitz J, Kasimir-Bauer S, Loehberg C.R, Rack B, Schneeweis A, Fehm T. Comparison of estrogen and progesterone receptor status of circulating tumor cells and the primary tumor in metastatic breast cancer patients. Gynecol Oncol. 2011; 122:356-60.

33. Peeters DJ, De Laere B, Van den Eynden GG, Van Laere SJ, Rothé F, Ignatiadis M, Sieuwerts AM, Lambrechts D, Rutten A, van Dam PA, Pauwels P, Peeters M, Vermeulen PB, et al. Semiautomated isolation and molecular characterisation of single or highly purified tumour cells from CellSearch enriched blood samples using dielectrophoretic cell sorting. Br J Cancer. 2013; 108:1358-67.

34. Polzer B, Medoro G, Pasch S, Fontana F, Zorzino L, Pestka A, Andergassen U, Meier-Stiegen F, Czyz ZT, Alberter B, Treitschke S, Schamberger T, Sergio M, et al. Molecular profiling of single circulating tumor cells with diagnostic intention. EMBO Mol Med. 2014; 6:1371-86.

35. Markou A, Farkona S, Schiza C, Efstathiou T, Kounelis S, Malamos N, Georgoulias V, Lianidou E. PIK3CA mutational status in circulating tumor cells can change during disease recurrence or progression in patients with breast cancer. Clin Cancer Res. 2014; 20:5823-34.

36. Kallergi G, Agelaki S, Kalykaki A, Stournaras C, Mavroudis D, Georgoulias V. Phosphorylated EGFR and PIK3CA/Akt signaling kinases are expressed in circulating tumor cells of breast cancer patients. Breast Cancer Res. 2008; 10:R80.

37. Strati A, Markou A, Parisi C, Mavroudis D, Georgoulias V, Lianidou E. Gene expression profile of circulating tumor cells in breast cancer by RT-qPCR. BMC Cancer. 2011; 11:422.

38. de Albuquerque A, Kaul S, Breier G, Krabisch P, Fersis N. Multimarker analysis of circulating tumor cells in peripheral blood of metastatic breast cancer patients: A step forward in personalized medicine. Breast Care. 2012; 7:7-12.

39. Wang H, Molina J, Jiang J, Ferber M, Pruthi S, Jatoke T, Derecho C, Rajpurohit Y, Zheng J, Wang Y. Gene expression markers in circulating tumor cells may predict bone metastasis and response to hormonal treatment in breast cancer. Mol Clin Oncol. 2013; 1:1031-38.

40. Kalykaki A, Agelaki S, Kallergi G, Xyrafas A, Mavroudis D, Georgoulias V. Elimination of EGFR-expressing circulating tumor cells in patients with metastatic breast cancer treated with gefitinib. Cancer Chemother Pharmacol. 2014; 73:685-93.

41. Fina E, Callari M, Reduzzi C, D`Aiuto F, Mariani G, Generali D, Pierotti MA, Daidone MG, Cappelletti V. Gene expression profiling of circulating tumor cells in breast cancer. Clin Chem. 2015; 61:278-89.

42. Powell AA, Talasaz AH, Zhang H, Coram MA, Reddy A, Deng G, Telli ML, Advani RH, Carlson RW, Mollick JA, Sheth S, Kurian AW, Ford JM, et al. Single cell profiling of circulating tumor cells: transcriptional heterogeneity and diversity from breast cancer cell lines. PloS One. 2012; 7:e33788.

43. Lowes LE, Allan AL. Recent advances in the molecular characterization of circulating tumor cells. Cancers (Basel). 2014; 6:595-624.

44. Yu M, Stott S, Toner M, Maheswaran S, 2 and Haber DA. Circulating tumor cells: approaches to isolation and characterization. J Cell Biol. 2011; 192:373-82.

45. Wallwiener M, Hartkopf AD, Riethdorf S, Nees J, Sprick MR, Schoenfisch B, Taran FA, Heil J, Sohn C, Pantel K, Trumpp A, Schneeweiss A. The impact of HER2 phenotype of circulating tumor cells in metastatic breast cancer: a retrospective study in 107 patients. BMC Cancer. 2015; 15:403.

46. Markou A, Strati A, Malamos N, Georgoulias V, Lianidou E. Molecular characterization of circulating tumor cells in breast cancer by a liquid bead array hybridization assay. Clin Chem. 2011; 57:421-30.

47. Mego M, Gao H, Bang-Ning L, Cohen EN, Tin S, Giordano A, Wu Q, Liu P, Nieto Y, Champlin RE, Hortobagyi GN, Cristofanilli M, Ueno NT, et al. Prognostic value of EMTcirculating tumor cells in metastatic breast cancer patients undergoing high-dose chemotherapy with autologous hematopoietic stem cell transplantation. J Cancer. 2012; 3:369-80.

48. Kallergi G, Mavroudis D, Georgoulias V, Stournaras C. Phosphorylation of FAK, PI-3K, and impaired action organization in CK-positive micrometastatic breast cancer cells. Mol Med. 2007; 13:79-88.

49. Narayan M, Wilken JA, Harris LN, Baron AT, Kimbler KD, Maihle NJ. Trastuzumab-induced HER reprogramming in "resistant" breast carcinoma cells. Cancer Res. 2009; 69:2191-94 
50. Sergina NV, Moasser MM. The HER family and cancer: emerging molecular mechanisms and therapeutic targets. Trends Mol Med. 2007; 13:527-34.

51. Tsang RY, Finn RS. Beyond trastuzumab: novel therapeutic strategies in HER2-positive metastatic breast cancer. Br J Cancer. 2012; 106:6-13.

52. Monteiro IP, Madureira P, de Vasconscelos A, Pozza DH, de Mello RA. Targeting HER family in HER2-positive metastatic breast cancer: potential biomarkers and novel targeted therapies. Pharmacogenomics. 2015; 16:257-71.

53. Li X, Lewis MT, Huang J, Gutierrez C, Osborne CK, Wu MF, Hilsenbeck SG, Pavlick A, Zhang X, Chamness GC, Wong H, Rosen J, Chang JC: Intrinsic resistance of tumorigenic breast cancer cells to chemotherapy. J Natl Cancer Inst. 2008; 100:672-79.

54. Zhang J, Zhang XB, Liu Y, Liu JJ, Zhang MS: Effects of an mTOR inhibitor RAD001 on human breast cancer stem cells in vitro and in vivo. J Clin Oncol. 2011; 29:e11514.

55. Ithimakin S, Day KC, Malik F, Zen Q, Dawsey SJ, BersanoBegey TF, Quraishi AA, Ignatoski KW, Daignault S, Davis A, Hall CL, Palanisamy N, Heath AN, et al. HER2 drives luminal breast cancer stem cells in the absence of HER2 amplification: implications for efficacy of adjuvant trastuzumab. Cancer Res. 2013; 73:1635-46.

56. Budd GT, Cristofanilli M, Ellis MJ, Stopeck A, Borden E, Miller MC, Matera J, Repollet M, Gerald V. Doyle GV, Terstappen L, Hayes DF. Circulating tumor cells versus imaging - predicting overall survival in metastatic breast cancer. Clin Cancer Res. 2006; 12:6403-9.

57. Liu MC, Shields PG, Warren RD, Cohen P, Wilkinson M, Ottaviano Y, Rao SB, Eng-Wong J, Seillier-Moiseiwitsch F, Noone AM, Isaacs C. Circulating tumor cells: a useful predictor of treatment efficacy in metastatic breast cancer. 2009; J Clin Oncol. 27:5153-9.

58. Mostert B, Sieuwerts AM, Kraan J, Bolt-de Vries J, van der Spoel P, van Galen A, Peeters DJ, Dirix LY, Seynaeve CM, Jager A, de Jongh FE, Hamberg P, Stouthard JM, et al. Gene expression profiles in circulating tumor cells to predict prognosis in metastatic breast cancer patients. Ann Oncol. 2015; 26:510-6.

59. Onstenk W, Sieuwerts AM, Weekhout M, Mostert B, Reijm EA, van Deurzen CH, Bolt-de Vries JB, Peeters DJ, Hamberg P, Seynaeve C, Jager A, de Jongh FE, Smid M, et al. Gene expression profiles of circulating tumor cells versus primary tumors in metastatic breast cancer. Cancer Lett. 2015; 362:36-44.

60. Meng S, Tripathy D, Shete S, Ashfaq R, Haley B, Perkins S, Beitsch P, Khan A, Euhus D, Cynthia Osborne C, Frenkel E, Hoover S, Leitch M, et al. HER-2 gene amplification can be acquired as breast cancer progresses. Proc Natl Acad Sci. 2004; 101:9393-8.

61. Hartkopf AD, Banys M, Fehm T. HER2-positive DTCs/ CTCs in breast cancer. Recent Results Cancer Res. 2012; 195:203-215.
62. Kallergi G, Agelaki S, Papadaki MA, Nasias D, Matikas A, Mavroudis D, Georgoulias V. Expression of truncated human epidermal growth factor receptor 2 on circulating tumor cells of breast cancer patients. Breast Cancer Res. $2015 ; 17: 113$

63. Zhang J, Li B, Yang Q, Zhang P, Wang H. Prognostic value of Aurora Kinase A (AURKA) expression among solid tumor patients: a systematic review and meta-analysis. Jpn J Clin Oncol. 2015; 45:629-36

64. Salomon DS, Brandt R, Ciardiello F, Normanno N. Epidermal growth factor-related peptides and their receptors in human malignancies. Crit Rev Oncol Hematol. 1995; 19:183-232.

65. Masuda H, Zhang D, Bartholomeusz C, Doihara H, Hortobagyi GN, Ueno NT. Role of epidermal growth factor receptor in breast cancer. Breast Cancer Res Treat. 2012; 136:331-45.

66. Sainsbury JR, Farndon JR, Needham GK, Malcolm AJ, Harris AL. Epidermal-growth-factor receptor status as predictor of early recurrence of and death from breast cancer. Lancet. 1987; 1:1398-402.

67. Guérin M, Gabillot M, Mathieu MC, Travagli JP, Spielmann M, Andrieu N, Riou G. Structure and expression of c-erbB-2 and EGF receptor genes in inflammatory and non-inflammatory breast cancer: prognostic significance. Int J Cancer. 1989; 43:201-8.

68. Dent R, Trudeau M, Pritchard KI, Hanna WM, Kahn HK, Sawka CA, Lickley LA, Rawlinson E, Sun P, Narod SA. Triple-negative breast cancer: clinical features and patterns of recurrence. Clin Cancer Res. 2007; 13:4429-34.

69. Rakha EA, El-Sayed ME, Green AR, Lee AH, Robertson JF, Ellis IO. Prognostic markers in triple-negative breast cancer. Cancer. 2007; 109:25-32.

70. Burness ML, Grushko TA, Olopade OI. Epidermal growth factor receptor in triple-negative and basal-like breast cancer: promising clinical target or only a marker? Cancer J. 2010; 16:23-32.

71. Zhang D, La Fortune TA, Krishnamurthy S, Esteva FJ, Cristofanilli M, Liu P, Lucci A, Singh B, Hung MC, Hortobagyi GN, Ueno NT. EGFR tyrosine kinase inhibitor reverses mesenchymal to epithelial phenotype and inhibits metastasis in inflammatory breast cancer. Clin Cancer Res. 2009; 15:6639-48.

72. Khambata-Ford S, O'Shaughnessy J, Brickman D, Jensen JD, Asmar L, Horak CE. Candidate predictive biomarkers of cetuximab benefit in triple negative breast cancer. J Clin Oncol. 2010; 28:abstr 1056.

73. Carey LA, Rugo HS, Marcom PK, Mayer EL, Esteva FJ, Ma CX, Liu MC, Storniolo AM, Rimawi MF, Forero-Torres A, Wolff AC, Hobday TJ, Ivanova A, et al. TBCRC 001: randomized phase II study of cetuximab in combination with carboplatin in stage IV triple-negative breast cancer. J Clin Oncol. 2012; 30:2615-23. 
74. Ellis IO, Schnitt SJ, Sastre-Garau X, Bussolati G, Tavassoli FA. Invasive breast carcinoma. In World Health Organization classification of tumours. Tumours of the breast and female genital organs. IARC Press. 2003; 13-59.

75. Sobin LH, Wittekind C: International Union against Cancer. In TNM Classification of Malignant Tumours. Ed 6. New York: Wiley-Liss; 2002.
76. Lal P, Salazar PA, Hudis CA, Ladanyi M, Chen B. HER-2 testing in breast cancer using immunohistochemical analysis and fluorescence in situ hybridization: a single-institution experience of 2,279 cases and comparison of dual-color and single-color scoring. Am J Clin Pathol. 2004; 121:631-6. 